\title{
CORTICOSTEROIDS IN THE MANAGEMENT OF FOOT-DROP IN LEPROMATOUS LEPROSY: A CASE REPORT
}

\author{
W. H. Jopl.ing, M.R.C.P. (Lond. \& Edin.), D.T.M. \& H. \\ The Jordan Hospital, Earlswood, Surrey,
}

In February, 1958, a West Indian aged 21, who had been treated for leprosy in England during the previous 13 months, was referred to the Hospital for Tropical Diseases for further management. On examination he was found to have skin changes of resolving lepromatous leprosy, there was anaesthesia of legs and feet, and both common peroneal (lateral popliteal) nerves felt firm and slightly thickened, the left more than the right. There was no muscular weakness nor wasting. There were moderate numbers of acid-fast bacilli in skin smears, the bacilli showing granular changes, and skin biopsy was typical of lepromatous leprosy.

As the patient refused admission to the Jordan Hospital, treatment had to be planned on an out-patient basis, and this made it impracticable to continue the twice-weekly sulphetrone injections which he had been receiving. Treatment was changed to $50 \mathrm{mg}$. by mouth of dapsone (DDS) every other day, and a fortnight later the dose was increased to $50 \mathrm{mg}$. daily. One month later he appeared to be progressing well, and the dosage was increased to $100 \mathrm{mg}$. alternating daily with $50 \mathrm{mg}$. Two wecks later he reported to say that, since his last attendance, he had felt unwell, had noticed "red lumps" on his skin, and had developed increasing weakness in his left foot. He was found to have erythema nodosum leprosum and a complete dropped foot; he had lost the power to dorsiflex or to evert his left foot, but inversion and plantar flexion were not affected. The left common peroneal nerve, contrary to expectation, was not tender.

He was admitted to the Jordan Hospital as an emergency, and the following treatment was instituted: (1) cessation of sulphone therapy; (2) prednisone $5 \mathrm{mg}$. four times daily by mouth; (3) a Plaster of Paris back splint supporting his foot at a right-angle. The plaster splint was removed twice daily in order to carry out passive movements; (4) an intraneural injection consisting of 1500 units of hyalase dissolved in $1 \mathrm{ml}$. of $2 \%$ procaine and mixed with $1 \mathrm{ml}$. of hydrocortisone suspension $(25 \mathrm{mg} . / \mathrm{ml}$.). This was injected into the left common peroneal nerve at the neck of the fibula.

Two days later contraction could be felt in the anterior and lateral crural muscles when he attempted to dorsiflex and evert his foot, and by the end of a week he was able to dorsiflex the foot almost to a right-angle, but moderate pressure with the hand could push the foot down again. At this stage active exercises were increased by getting him to use his foot on a player piano, and he continued to wear the plaster splint when not exercising. Muscle power continued 
to improve, and a fortnight lạter (threc weeks after admission) he was able to dorsiflex his foot to a right-angle and all his toes were capable of slight dorsiflexion. The dosage of prednisone was reduced to $15 \mathrm{mg}$. daily, the splint was worn at night only, and active exercises were continued. One week later the dosage of prednisone was reduced to $10 \mathrm{mg}$. daily, and this was progressively decreased to nil over the next two weeks.

Dr. W. D. Fletcher, of the Department of Physical Medicine at University College Hospital, saw the patient 5 weeks after admission and reported as follows:

"I have carried out electrical reactions on his muscles this week and I am pleased to say that these were quite normal. He must have, therefore, a neuropraxia, and I would expect him to get a complete recovery."

One week later he was able to dorsiflex and evert his foot fully, the strength of the affected muscles being about three-quarters that of the muscles on the opposite side. By this time prednisone had

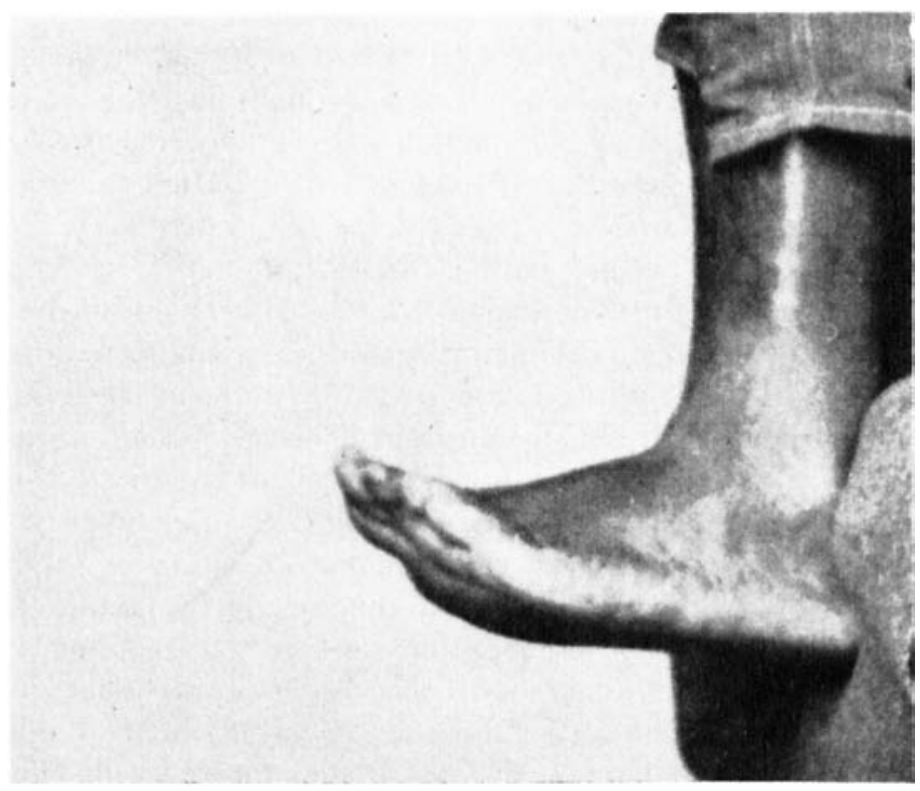

Recovery from foot-drop after treatment as described

been discontinued and the splint discarded. Two weeks later ( 8 weeks after admission) the muscular power of the left foot was equal to that of the right, the only detectable difference being slight weakness in dorsiflexing the left big toe, but this recovered completely within the next few weeks.

Resumption of anti-leprosy treatment was considered at this stage, and it was decided not to resume sulphone therapy but to 
change to Ciba 1906. There has been no recurrence of neuritis during the subsequent 12 months although there have been several bouts of erythema nodosum leprosum.

\section{Discussion}

Damage to peripheral nerves in lepromatous leprosy takes the form of fibrous thickening of the connective tissue composing the endoneurium, perineurium and epineurium, and this takes place at sites where the affected nerves are superficial in their course. The basic architecture of the nerves is maintained in the earlier stages, and damage to nerve fibres results from compression. An allergic type of reaction may take place in one or more of the affected nerves during the course of treatment, either as an isolated event or in conjunction with a more generalized reaction, in which oedema is the characteristic feature. This causes a rapid increase in the compression of nerve fibres as the connective tissue thickening prevents expansion taking place, and, if permanent damage to nerve fibres is to be prevented, it is essential to relieve this compression as quickly as possible. Corticosteroid therapy stops further development of oedema by reducing capillary permeability, and an intraneural injection of hyalase, by virtue of its spreading action, causes a dispersal of the oedema which is already present. Wilkinson and Colombo (1955) and Garrett (1956) have described the successful use of hyalase injected into painful nerves in lepromatous leprosy; Jopling and Cochrane (1957) have advocated intraneural injections of hydrocortisone. It is now standard practice at this hospital to give a single intraneural injection consisting of procaine, hyalase and hydrocortisone, as described in this case report, and this gives long-lasting relief of pain without having to stop specific therapy. Results are equally satisfactory when pain is associated with muscle weakness, but in such cases it is necessary to stop specific treatment temporarily and to splint the affected muscles when they are not being exercised.

This routine was followed in the case under discussion, but systemic corticosteroid treatment was given in addition, to control erythema nodosum and to ensure that intraneural oedema did not recur during the stage of recovery.

I would like to thank Sir George McRobert for permission to publish this case, and Dr. W. D. Fletcher for his report, and $\mathrm{Mr}$. Frank Barratt for the photography.

\section{References}

Garrett, A. S. (1956) Leprosy' Review, 27, 61.

Jopling, W. H. and Cochrane, R. G. (1957) Ibid., 28, 5.

Wilkinson, F. and Colombo, V. (1955) Orientación Méd., 4, 342. (Reviewed in Internat. J. Leprosy, 1955, 23, 232.) 